\title{
DETERMINANTES DAS PRÁTICAS DE GOVERNANÇA CORPORATIVA: UM ESTUDO NAS EMPRESAS REGISTRADAS NA CVM ${ }^{1}$
}

\author{
Patrícia Vasconcelos Rocha Mapurunga² \\ Vera Maria Rodrigues Ponte ${ }^{3}$ \\ Marcelle Colares Oliveira ${ }^{4}$
}

Resumo: Investigou-se a associação entre as práticas de governança corporativa e as características das 554 empresas de capital aberto não financeiras registradas na CVM na posição de 31/12/2011. Para tanto, a partir das recomendações do IBGC e da CVM, criou-se um índice de governança corporativa composto por 21 perguntas binárias e objetivas, abrangendo três dimensões: composição e funcionamento do conselho de administração, propriedade e direitos dos acionistas e transparência. Os dados coletados foram submetidos a análises descritivas e de regressão. Verificou-se baixa aderência das companhias às boas práticas de governança corporativa, já que atenderam, em média, a apenas $36,23 \%$ das práticas requeridas. A partir da análise de regressão, verificou-se associação positiva entre a governança corporativa e as variáveis endógenas tamanho, endividamento, oportunidade de crescimento, listagem na BM \& FBovespa e participação nos Níveis Diferenciados de Governança Corporativa, e uma associação negativa com as variáveis tangibilidade e tempo de existência. Ademais, verificou-se que as variáveis endógenas podem ser diferir entre as empresas listas e não listadas em bolsa. Os resultados apresentados ratificam trabalhos anteriores que verificaram associação entre as práticas de governança corporativa e as características das firmas. O presente trabalho diferencia-se dos demais por analisar tanto as empresas listadas quanto as não listadas em bolsa.

Palavras-chave: Governança Corporativa. Mercado de Capitais. Empresas Brasileiras.

Uma versão inicial do artigo foi publicada no Congresso Anpcont 2013

${ }^{2}$ E- mail: pattivasconcelos@hotmail.com. Tribunal de Contas do Estado do Ceará

${ }^{3}$ E-mail: vponte@fortalnet.com. Universidade Federal do Ceará.

${ }^{4}$ E-mail: marcellecolares@uol.com.br. Universidade Federal do Ceará. 


\title{
DETERMINANTS OF CORPORATE GOVERNANCE PRACTICES: A STUDY IN COMPANIES REGISTERED IN THE CVM
}

\begin{abstract}
We investigated the association between corporate governance practices and characteristics of 554 public companies, that are not finance companies, registered within the CVM in position 31/12/2011. To this end, based on the recommendations of the IBGC and CVM, we created a corporate governance index composed of 21 binary and objective questions covering three dimensions: composition and functioning of the board of directors, property and rights of shareholders and transparency. The collected data was subjected to descriptive analysis and regression analysis. From the data was detected low compliance of the companies to good corporate governance practices, since on average they merely observed only $36.23 \%$ of the required corporate governance practices. From the regression analysis was verified a positive association between corporate governance and the endogenous variables size, debt, growth opportunity, listing on the BM \& FBovespa and participation in the corporate Governance Differentiated Levels, in addition to a negative association with the variables tangibility and time of existence. Furthermore, it was found that the endogenous variables can be differ between the companies that are listed on the stock exchange and the ones that are not listed in the stock exchange. The results presented confirm previous work that found an association between corporate governance practices and characteristics of firms. This study differs from the others by analyzing both the companies listed as non-listed.
\end{abstract}

Keywords: Corporate Governance. Capital Markets. Brazilian Companies. 


\section{INTRODUÇÃO}

J ensen e Meckling (1976, p. 05) definem a relação de agência como "um contrato sob o qual uma ou mais pessoas (o principal (s)) envolve outras pessoas (o agente) para desempenhar algum serviço em seu nome que envolva delegação de autoridade na tomada de decisão". Em ambas as partes sendo maximizadoras de utilidades, nem sempre seus interesses serão alinhados, e, nesse contexto, surgem relações conflituosas entre o principal (acionista) e o agente (gestor), as quais são denominadas conflitos de agência.

Healy e Palepu (2001) propõem alternativas para solucionar os problemas de agência, como a realização de contratos entre administradores e proprietários, o monitoramento das decisões dos administradores pelo conselho de administração e a disponibilização de informações.

A solução via contratos pode não se dar em virtude da imperfeição dos contratos (Shleifer; Vishny, 1997). Quanto ao conselho de administração, trata-se de um mecanismo de governança incumbido de controlar a alta gestão, ratificando as decisões relevantes e monitorando a gerência (Silveira, 2002). Sobre a disponibilização de informações, Cunha e Ribeiro (2008) preceituam que servem como um monitoramento da administração por parte dos investidores externos, haja vista que diminuem a assimetria informacional entre as partes.

Para Almeida e Santos (2008, p. 18) a possibilidade de conflitos de agência"faz com que os investidores sejam mais cautelosos na aplicação dos recursos e busquem empresas que tenham melhores práticas de governança corporativa, para que não sejam expropriados pelos gestores e acionistas controladores". Assim, a governança corporativa torna-se importante como forma de minimizar esses conflitos, pois pode gerar segurança perante o público externo (acionistas, credores...), seja pela maior transparência e confiabilidade das informações, seja pelas regras impostas pela boa governança.

Segundo Shleifer e Vishny (1997), a governança corporativa dedica-se ao conjunto de relações entre a direção das organizações, seus conselhos de administração, seus acionistas e outras partes interessadas, estabelecendo caminhos pelos quais os financiadores do negócio assegurarão o retorno de seu investimento.

Em contextos de crises econômicas, quando as empresas precisam captar recursos para financiar suas atividades, a governança corporativa pode se mostrar como um diferencial na busca por investidores. Isso é corroborado por Correia, Amaral e Louvet (2011, p. 45) que entendem que "a eficiência da governança aumenta a proteção dos interesses dos investidores contra o risco de espoliação pelos dirigentes oportunistas", o que fica mais evidente com empresas como as brasileiras, que necessitam de recursos de investidores estrangeiros.

Contrapondo-se a essa necessidade das empresas brasileiras, Black, Carvalho e Gorga (2010) constataram que muitas delas não possuem fatores associados à boa governança, pois não têm independência do conselho, possuem divulgação financeira aquém dos padrões internacionais, não possuem comitês de auditoria, entre outros. Por outro lado, Lameira e Lee Ness Jr. (2011) colocam que, no mercado interno, diversas companhias abertas já melhoraram seu sistema de governança no intuito de captar recursos mais baratos e em maior volume no mercado de capitais nacional. 
Assim, diante dos benefícios da adoção de boas práticas de governança, como aumento da transparência, redução da assimetria de informação, proteção aos acionistas e aumento da confiança dos investidores, questiona-se os fatores associados a essa decisão das empresas, em que umas prezam pela boa qualidade da sua governança e outras não.

Conforme estudos brasileiros e estrangeiros, a adoção dessas práticas é determinada por variáveis endógenas, como tamanho (Klapper \& Love, 2002; Ariff, Ibrahim e Othman, 2007; Leão, 2010), tangibilidade (Klapper \& Love, 2002; Almeida et al., 2010a), desempenho (Silva \& Leal, 2004; Silveira, Barros e Perobelli, 2008), oportunidades de crescimento (Klapper \& Love, 2002; Durnev \& Kim, 2005; Almeida et al., 2010a), emissão de American Depositary Receipts - ADR (Silveira \& Barros, 2008; Silveira et al., 2009; Leão, 2010) e idade da empresa (tempo de existência) (Almeida et al., 2010a; Leão, 2010).

Em referidas investigações, a qualidade das práticas de governança foi medida por índices elaborados pelos autores contemplando várias dimensões da governança, pela utilização de índices já explanados por outros autores, ou mesmo foram baseados em scores elaborados por agências de rating ou por bancos de investimento.

Diante desse cenário, a presente pesquisa objetiva investigar a associação entre a adoção de boas práticas de governança corporativa e as características das companhias registradas na CVM, incluindo empresas listadas e não listadas em bolsa.

Silva e Leal (2004) entendem que o Brasil é um caso particularmente interessante de analisar, pelo fato de os debates sobre as estruturas de governança corporativa terem se intensificado na última década, quando fatores como privatizações, abertura da economia e entrada de novos investidores, especialmente os estrangeiros e institucionais, têm estimulado esforços no sentido da adoção de melhores práticas de governança corporativa. Já Black, Carvalho e Gorga (2010) afirmam que esse interesse reside no tamanho do Brasil, nos grandes benefícios privados de controle e na relativamente fraca governança corporativa.

Essa busca também justifica-se devido ao fato de os fracos mecanismos de governança serem “apontados como uma das causas do baixo desenvolvimento do mercado acionário brasileiro" (Carvalho, 2002, p. 19). Corroborando nessa direção, Braga-Alves e Shastri (2011) apresentam estudos que têm fornecido evidências da importância da governança corporativa em países onde existe má proteção dos investidores, bem como estudos que apontam o efeito positivo da governança corporativa sobre o valor das empresas em mercados emergentes.

A opção por uma população com essas características constitui um diferencial, já que outras pesquisas similares no Brasil limitaram-se às empresas listadas na BM\&FBovespa, desconsiderando, portanto, significativa parcela do grupo de companhias registradas na CVM. Assim, o presente estudo contribui para o aprimoramento da literatura sobre os determinantes das boas práticas de governança corporativa no Brasil, preenchendo uma lacuna existente quanto aos determinantes da adoção dessas práticas nas empresas não listadas em bolsa.

Registre-se que Almeida et al. (2010b, p. 910) dispõem que as empresas não listadas em bolsa representam expressiva parcela do conjunto das empresas de capital aberto do país, com relevante participação na economia brasileira, merecendo, portanto, serem estudadas, pois "são, em potencial, as empresas que podem fortalecer e incrementar o mercado de capitais brasileiro". Os autores analisaram as práticas de governança corporativa adotadas pelas empresas não listadas, sem, no entanto, procurar identificar os seus determinantes.

O artigo foi estruturado em cinco tópicos, incluindo a introdução. No segundo, apresenta-se o referencial teórico e, no tópico subsequente, os procedimentos metodológicos; o quarto tópico traz os resultados; e o quinto apresenta a conclusão. 


\section{REFERENCIAL TEÓRICO}

\subsection{PRÁTICAS DE GOVERNANÇA CORPORATIVA}

Lameira e Lee Ness Jr. (2011, p. 34) colocam que, em meio ao processo de globalização dos mercados, ao longo dos últimos anos "várias empresas brasileiras promoveram melhoria das suas práticas de governança de modo a captarem recursos nos mercados de crédito e capitais internacionais". Isso é justificado porque, de um lado tem a empresa, com necessidade de captar recursos, e de outro o investidor, que procura investimentos seguros, além de rentáveis.

Conforme aponta Silveira (2002, p. 23) a governança corporativa se relaciona a mecanismos internos e externos capazes de assegurar que as "decisões corporativas serão tomadas no melhor interesse dos investidores, de forma a maximizar a probabilidade dos fornecedores de recursos obterem para si o retorno sobre seu investimento" (Silveira, 2002, p. 23). Ou seja, ela fornece mecanismos para que o investidor monitore a organização e avalie a probabilidade de retorno dos seus investimentos.

Kapler e Love (2002) afirmam que há indícios de que a governança corporativa pode suprir parcialmente a fraca proteção legal aos investidores, o que foi sugerido nos resultados do estudo de Durnev e Kim (2005). Essa fraca proteção legal fica muito evidente quando ocorrem escândalos corporativos envolvendo a alta gestão, como ocorreram em empresas como Enron, Global Crossing, Qwest Tyco, Kmart etc.

Nesse processo, os investidores passam a desconfiar das organizações, e, pela pluralidade de opções de investimento, interno e externo, direcionam-se às empresas confiáveis. No Brasil, já ocorreram escândalos corporativos, como Parmalat, em 2003, e Banco Santos, em 2004, que expuseram a fragilidade das organizações e a necessidade da adoção efetiva de boas práticas de governança corporativa.

Silveira (2002, p. 23) coloca que, pela governança corporativa pode-se verificar se as "decisões corporativas serão tomadas no melhor interesse dos investidores, de forma a maximizar a probabilidade de os fornecedores de recursos obterem para si o retorno sobre seu investimento".

Sem boas práticas de governança corporativa, os acionistas, principalmente os minoritários, cujos recursos tornam-se cada vez mais relevantes às empresas, ficam numa situação de insegurança, pois geralmente não possuem informações privilegiadas, devendo confiar naquilo que foi oficialmente publicado. Assim, Carvalho (2003, p.02) afirma que "a participação de minoritários está condicionada à eficácia da proteção aos seus direitos: regras adequadas, transparência de informação e enforcement".

Black, Carvalho e Gorga (2012) ressaltam que a governança corporativa nas empresas brasileiras ainda é baixa, embora esteja mudando rapidamente. Leão (2010, p. 25) aponta como marcos da adoção dessas práticas "a abertura da economia brasileira ao exterior; o aumento dos investimentos externos no país; o crescente acesso das companhias brasileiras ao mercado externo; o processo de privatização; e o Plano Real (eliminação da alta inflação)". Já Aragão et al. (2012) incluem a publicação do Código das Melhores Práticas de Governança Corporativa do IBGC, a edição da Lei n. 10.303/2001, a Cartilha de Recomendações da CVM, em 2002, bem como a criação dos NDGC pela BM\&FBovespa, no ano 2000.

Nesse contexto, são importantes estudos que ajudem a compreender a decisão dos gestores pela adoção de boas práticas de governança. Braga-Alves e Shastri (2011) apresentam estudos que têm fornecido evidências da importância da governança corporativa em países onde existe má proteção dos investidores, bem como estudos que apontam o efeito positivo da governança corporativa sobre o valor das empresas em mercados emergentes. 


\subsection{ESTUDOS EMPÍRICOS ANTERIORES}

Estudos empíricos anteriores já relacionaram as características das empresas às suas práticas de governança corporativa. Nessa linha, suas características, variáveis endógenas como tamanho, desempenho, endividamento, entre outros, mostraram-se associadas à governança. A seguir, serão descritos alguns desses estudos.

Klapper e Love (2002): Após analisar 495 firmas de 25 mercados emergentes, os autores concluíram que: uma melhor governança corporativa está altamente correlacionada com melhor desempenho operacional e avaliação de mercado; as empresas situadas em um ambiente de baixa proteção legal ao investidor adotam menores níveis de governança; e a governança está correlacionada com o tamanho da firma, a tangibilidade dos ativos e as oportunidades de crescimento.

Silva e Leal (2004): A partir das empresas listadas na BM\&FBovespa entre 1998 e 2002, os autores concluíram que menos de $4 \%$ dessas empresas adotam "boas" práticas de governança corporativa e que aquelas com melhor governança têm desempenho significativamente superior aos das demais. Assim, o desempenho seria uma variável associada positivamente às boas práticas de governança.

Durnev e Kim (2005): Após pesquisar 859 firmas de 27 países no ano 2000, os autores verificaram que os atributos oportunidades de crescimento, necessidade de financiamento externo e estrutura de propriedade estão relacionados com a qualidade da governança e com a transparência, bem como que as ações de empresas com maior governança e transparência são mais valorizadas.

Ariff, Ibrahim e Othman (2007): Os autores investigaram se há diferenças, nas melhores e piores empresas da Malásia, quanto às práticas de governança corporativa nas características rentabilidade, alavancagem, crescimento, valorização de mercado, tamanho, idade da empresa, estrutura de propriedade e países de operação, o que foi evidenciado apenas quanto à variável tamanho. Ou seja, nas empresas pesquisadas, apenas a variável tamanho mostrou associação com as boas práticas de governança.

Silveira e Barros (2008): Analisando companhias brasileiras, os autores constataram, por exemplo, que as empresas maiores, emissoras de ADR e com melhor desempenho apresentam, em média, maior governança.

Silveira et al. (2009):Tomando por base as empresas da BM\&FBovespa entre 1998 a 2004, os autores observaram associação positiva entre governança corporativa e a adesão aos NDGC e a emissão ADR.

Almeida et al. (2010a): A partir das empresas brasileiras de capital aberto com investimento público em 2006 e 2007, os autores verificaram que a qualidade da governança corporativa é impactada negativamente pela alavancagem, tangibilidade, crescimento e idade da empresa. Esses resultados se contrapõem a outros que verificaram associação positiva entre a governança e essas características, no entanto, o grupo de empresas utilizado nas amostras também foi bem diferente.

Leão (2010): A partir das empresas brasileiras de capital aberto entre 2003 a 2008, o autor identificou que a necessidade de financiamento externo e a estrutura de propriedade são importantes na determinação do nível de governança, bem como que tamanho, emissão de ADR, performance, estratégia de saída dos acionistas, idade da empresa e presença de investidores institucionais como grandes acionistas apresentaram significância para os modelos do estudo.

\subsection{CONSTRUÇÃO DAS HIPÓTESES DA PESQUISA}

A partir de estudos anteriores, Silveira, Barros e Perrobelli $(2008$, p. 6) admitem a possibilidade de que as empresas submetidas a um mesmo ambiente contratual "apresentem níveis diferentes de 
qualidade de governança corporativa, como função de suas características observáveis". Seguindo esse pressuposto, a qualidade das práticas de governança corporativa das empresas brasileiras pode estar associada a suas variáveis endógenas.

Corroborando nesse sentido, Silveira, Barros e Famá (2003, p. 59), entendem que empresas com governança corporativa mais adequada às recomendações dos códigos das melhores práticas "devem ter uma melhor gestão e, consequentemente, melhor desempenho financeiro do que empresas com uma estrutura de governança menos adequada, ceteris paribus".

Na mesma linha, Klapper e Love (2002) encontraram uma correlação positiva entre boa governança corporativa e desempenho operacional e os resultados de Silva e Leal (2004) também apoiam a hipótese de que as empresas com melhor governança corporativa apresentam desempenho significativamente superior (ROA).

Já, Silveira e Barros (2008, p. 6), assumindo que "quanto melhor o desempenho da empresa, melhor a governança corporativa esperada da empresa em virtude da menor expropriação dos acionistas externos", identificaram uma correlação positiva entre desempenho e nível de governança corporativa, mas ressaltaram ser "possível que empresas com desempenho ruim possam ter melhorado o nível de governança corporativa como forma de compensar o fraco desempenho financeiro", assinalando que os estudos com essas variáveis podem sofrer do problema econométrico conhecido como causalidade reversa.

Leão (2010) assumiu a hipótese de que empresas com baixo desempenho financeiro adotem tais práticas com o intuito de melhorá-lo, mas os resultados não foram conclusivos. Tomando por base esses pressupostos divergentes, Ariff, Ibrahim e Othman afirmam que não se pode prever muito sobre o sentido da relação entre essas variáveis, já que estudos anteriores mostram resultados mistos.

Nesse contexto, assume-se como hipótese que $\mathrm{H} 1$ : O desempenho possui associação com as boas práticas de governança corporativa.

O tamanho é também frequentemente apontado como determinante para as melhores práticas de governança, a exemplo de Ariff, Ibrahim e Othman (2007), Silveira e Barros (2008), Silveira et al. (2009), Almeida et al. (2010a) e Leão (2010).

Segundo Ariff, Ibrahim e Othman (2007), uma justificativa para a adoção dessa variável reside no fato de que as empresas maiores dispõem de mais recursos para implantar boas práticas de governança corporativa. Além disso, Durnev e Kim (2005) afirmam que o tamanho pode afetar a estrutura de governança pelo fato de que as grandes empresas tendem a atrair mais atenção e, portanto, podem estar sob maior controle por parte do público.

Por outro lado, para Klapper e Love (2002), tanto as grandes quanto as pequenas empresas recebem incentivos para adotar boas práticas de governança corporativa. No primeiro grupo, isso ocorre devido aos maiores custos de agência, o que as leva a adotar voluntariamente melhor governança corporativa, a fim de mitigar o problema. Nas pequenas, a ocorrência de incentivos se deve ao acelerado crescimento e à necessidade de financiamento externo, o que também pode levá-las a adotar melhores práticas de governança.

Esse entendimento foi seguido por Silveira et al. (2009), que identificaram uma correlação positiva entre tamanho e governança. Em sentido semelhante, Silveira e Barros (2008) e Ariff, Ibrahim e Othman (2007) também concluíram que as empresas maiores apresentam, em média, maior nível de governança corporativa. 
Diante dessas constatações, assume-se como hipótese que H2: $\mathrm{O}$ tamanho possui associação com as boas práticas de governança corporativa.

Assim como o desempenho e o tamanho, o nível de endividamento das firmas também pode estar associadoa sua governança corporativa. Segundo Silveira, Barros e Perobelli (2008, p. 765), a qualidade da governança corporativa "pode influenciar as decisões de financiamento na medida em que as empresas com melhor governança desfrutem de condições mais vantajosas para captar recursos externos".

Ou seja, os credores precisam ter segurança ao conceder crédito, e isso pode ser fornecido por práticas de governança corporativa, como transparência, regulação etc. Assim, Klapper e Love (2002) e Silveira e Barros (2008) entendem que a empresa que precisa captar recursos deve apresentar uma boa governança corporativa. Logo, as empresas mais endividadas tendem a apresentar melhor estrutura de governança corporativa que as demais.

Assim, assume-se também como hipótese que H3: O endividamento possui associação com as boas práticas de governança corporativa.

Já Durnev e Kim (2005) afirmam que empresas com maior proporção de ativos intangíveis tendem a adotar normas mais rígidas de governança, pois esses ativos são mais difíceis de monitorar e mais fáceis de fraudar. Os autores identificaram correlação positiva entre proporção de ativos intangíveis e governança.

Para Silveira e Barros (2008 p. 4), empresas com alta proporção de ativos intangíveis tem mais estímulo para adotar melhores práticas de governança, devido à "maior necessidade de sinalizar aos investidores que não pretendem fazer mau uso dos seus ativos no futuro".

Por outra perspectiva, as empresas com maior proporção de ativos tangíveis tendem a estabelecer mecanismos de governança mais frágeis, já que esses ativos são mais fáceis de controlar e mais difíceis de desviar. Seguindo essa linha, Klapper e Love (2002) adotaram o pressuposto de que se deve observar uma correlação negativa entre a proporção de ativos fixos e as práticas de governança corporativa, o que foi verificado por Almeida et al. (2010a).

Ante os resultados apresentados, assume-se como hipótese que H4: A tangibilidade possui associação com as boas as práticas de governança corporativa.

As oportunidades de crescimento da empresa aparecem também como uma variável associada à governança corporativa. Segundo Silveira e Barros (2008, p. 4), é possível que"empresas com melhores oportunidades futuras de crescimento percebam uma maior utilidade na adoção de melhores práticas de governança do que empresas sem grandes expectativas de captação futura de recursos". Ou seja, para crescer, as empresas necessitam de maior financiamento externo, e, para consegui-lo, devem possuir boa governança corporativa.

Klapper e Love (2002) ressaltam que quanto mais oportunidades futuras de crescimento a empresa tiver, mais recursos ela precisará captar, devendo apresentar melhor nível de governança. Bhagat e Bolton (2008) afirmam que empresas com maiores oportunidades de crescimento tendem a possuir melhores estruturas de governança.

Já Dunerv e Kim (2005) verificaram que as oportunidades de investimento rentáveis levam a melhores práticas de governança e Klapper e Love (2002) concluíram que as taxas de crescimento passadas estão associadas positivamente à boa governança. Ou seja, quanto maior a oportunidade de crescimento, melhor a governança corporativa.

Logo, assume-se como hipótese que H5: As oportunidades de crescimento possuem associação com as boas práticas de governança corporativa. 
Cita-se também como variável explicativa da governança corporativa o tempo de existência das empresas. Ariff, Ibrahim e Othman (2007) entendem que deve existir uma associação positiva entre essas variáveis, pois as empresas que operam há mais tempo possuem uma reputação que pode ser prejudicada pela falta de governança corporativa. Ademais, as empresas maduras têm bastante experiência e aprendizagem dos efeitos da má e da boa governança corporativa.

Indo de encontro a esses resultados, Almeida et al. (2010a) encontraram associação negativa entre governança corporativa e idade das empresas (tempo de existência); e Leão (2010) adotou a hipótese de que as empresas mais novas seriam estimuladas a adotar melhores práticas de governança corporativa, já que obteriam um maior benefício marginal do que aquele apurado por empresas mais antigas e já bem estabelecidas ao adotar tais práticas, mas os resultados não foram significantes. Já Black, Jang e Kim (2003) esperavam encontrar uma relação negativa entre a idade e a governança corporativa, mas os resultados mostraram o inverso.

Nesse contexto, também se assume a hipótese de que H6: O tempo de existência das empresas possui associação com as práticas de governança corporativa.

Outra variável recorrente nos estudos sobre as variáveis associadas à governança corporativa é a emissão de ADR. Para Silveira e Barros (2008, p. 6), as empresas que emitem ADR têm que se enquadrar a padrões mais rígidos de governança corporativa. Já Leão (2010) dispõe que a emissão de ADR pressupõe a adoção de requisitos de governança corporativa e Durnev e Kim (2005) diz que se espera dessas empresas melhor transparência e governança.

Silveira e Barros (2008), Leão (2010), Silveira et al. (2009) e Klapper e Love (2002) confirmaram a expectativa de uma relação positiva entre esse atributo e a adoção de boas práticas de governança corporativa. Ou seja, as empresas que emitem ADR tendem a apresentar melhor governança corporativa.

Assim, outra hipótese que se assume no presente estudo é que H7: A emissão de ADR possui associação com as boas práticas de governança corporativa.

A adoção de boas práticas de governança corporativa também pode ser sentida no cenário de abertura do capital, já que o número de proprietários aumenta e, em consequência, faz-se necessária uma administração mais transparente. Isso fica ainda mais evidente quando as ações dessas companhias são negociadas em bolsas, já que a propriedade fica mais dispersa e a adoção dessas boas práticas tende a ser um diferencial na decisão dos investidores.

Além disso, as empresas negociadas em bolsa precisam ser atrativas aos investidores, o que pode ocorrer com a adoção de boas práticas de governança, pois isso dará segurança aos investidores, reduzindo o risco da perda do investimento, além de minimizar potenciais problemas de agência entre as partes.

Tratando das companhias abertas nacionais, que buscam soluções para melhorar a gestão organizacional e afetar positivamente o desempenho da empresa, possibilitando aumento do retorno das suas ações, Lameira e Lee Ness Jr. (2011, p. 34) colocam que melhores práticas de governança "podem permitir a melhoria do processo de decisão nas empresas, além de proporcionar o aperfeiçoamento dos controles e uma maior eficiência gerencial, e assim viabilizar o atingimento dessas metas intermediárias".

Ademais, diferentemente das empresas não listadas em bolsa, as listadas submetem-se a regras específicas de governança, como os segmentos especiais de listagem da BM\&FBovespa, o que thes impõe maior comprometimento com essas práticas (Almeida et al., 2010b). Nesse contexto, entende-se que as companhias cujas ações são negociadas na BM\&FBovespa tendem a apresentar melhor governança corporativa que as demais. 
Assume-se, pois, como hipótese da presente pesquisa que H8: A listagem na BM\&FBovespa possui associação com as boas práticas de governança corporativa;

Por fim, outra variável que também pode influenciar a governança corporativa adotada nas empresas é a participação em segmentos especiais de listagem da BM\&FBovespa. A BM\&FBovespa classifica, como segmentos especiais de listagem, o Novo Mercado, o Nível 2 e o Nível 1, sendo que os dois primeiros são segmentos premium.

Lameira e Lee Ness Jr. (2011) colocam que as empresas ingressam nos Níveis Diferenciados de Governança Corporativa (NDGC) para mostrarem-se mais seguras para o ingresso de novos acionistas. Braga-Alvez e Shastri (2011) afirmam que as empresas listadas no Novo Mercado se comprometem a padrões mais elevados de governança corporativa, seguidas das empresas listadas no Nível 2 e no Nível 1, nessa ordem. Para embasar seus pressupostos, os autores utilizaram a justificativa de que, para classificar-se no Novo Mercado, a empresa deve apresentar "good practices of corporate governance".

Para Silveira et al. (2009), as empresas listadas nesses segmentos mais rígidos, principalmente Nível 2 e Novo Mercado, devem se comprometer com maior transparência e com melhores padrões de governança corporativa. Os resultados do estudo mostraram associação positiva entre a adesão voluntária a segmentos e a maior qualidade da governança corporativa.

Conforme Silveira e Barros (2008, p. 6), as empresas que aderem aos NDGC têm que se enquadrar a padrões mais rígidos de transparência e GC, devendo apresentar, em média, melhor GC. Já Black, Carvalho e Gorga (2010) dispõem que o Nível 1, Nível 2 e Novo Mercado possuem regras mais fortes de governança corporativa que o mínimo legal.

Logo, assume-se ainda que H9: A participação nos Níveis Diferenciados de Governança Corporativa possui associação com as boas práticas de governança corporativa.

\section{METODOLOGIA}

\subsection{POPULAÇÃO, AMOSTRA E COLETA DE DADOS}

A presente pesquisa enquadra-se como descritiva, adotando procedimentos documentais a partir de dados secundários provenientes dos portais eletrônicos das empresas da amostra, da CVM e da BM\&FBovespa (como relatórios anuais, estatutos, formulários de referência e atas de assembleias), bem como do sistema de informações Economática ${ }^{\circledR}$.

A população da pesquisa, que não incluiu o setor financeiro em razão da sua específica regulamentação exercida pelo Banco Central e ao forte enforcenment, reuniu as 554 empresas de capital aberto registradas na CVM em 31/12/2011. Essa população é um diferencial do presente estudo, visto que pesquisas similares incluíram na amostra apenas as empresas listadas na BM\&FBovespa, desconsiderando aquelas que, embora de capital aberto, não negociavam ações na BM\&FBovespa.

Foram excluídas do estudo 42 empresas que não apresentaram as informações necessárias para o cálculo do IGOV (tópico 3.3.1.), restando, pois, 512 empresas na amostra, das quais 344 estavam listadas na BM\&FBovespa e 168, não. 
Tabela 1: Amostra da pesquisa

\begin{tabular}{|c|c|c|c|}
\hline & No de Empresas & No de Empresas Listadas & No de Empresas não Listadas \\
\hline Amostra completa & 554 & 368 & 186 \\
\hline $\begin{array}{c}\text { Empresas excluídas por não apresentarem } \\
\text { informaçôes para cálculo do IGOV }\end{array}$ & 42 & 24 & 18 \\
\hline $\begin{array}{c}\text { Amostra utilizada para analisar a frequência das } \\
\text { informaçōes sobre o IGOV (tópico 4.1) }\end{array}$ & 512 & 344 & 168 \\
\hline $\begin{array}{c}\text { Empresas excluídas por insuficiência de dados ou por } \\
\text { apresentarem outliers }\end{array}$ & 84 & 48 & 36 \\
\hline Amostra para regressão (tópico 4.2) & 428 & 296 & 132 \\
\hline
\end{tabular}

Ademais, conforme tabela acima, na análise de regressão, dessas 512 empresas, foram excluídas 84. Dessas, 32 cujos foram excluídas porquê os dados referentes às variáveis independentes utilizadas na regressão (tópico 3.3.2) não estavam disponíveis e 52 empresas por apresentavam outliers. Logo, a regressão ficou reduzida a 428 empresas, sendo 296 listadas na BM\&FBovespa e 132, não.

Assim, a variável dependente (IGOV) foi calculada para a amostra completa, sendo feitas com essa amostra as análises descritas no tópico 4.1. Já a regressão, cuja análise encontra-se no tópico 4.2, foi feita apenas para 428 empresas que possuíam dados para tanto.

\subsection{MODELO, PROCESSAMENTO E ANÁLISE DOS DADOS IGOV}

De posse do IGOV, foram empregadas técnicas de estatística descritiva, possibilitando a realização de uma análise geral dos níveis de governança corporativa das empresas. Na sequência, utilizou-se análise de regressão para verificar se "um conjunto de variáveis ditas explicativas pode influenciar uma ou mais variáveis dependentes e, dessa forma, propiciar ao pesquisador a elaboração de modelos de previsão" (Fávero et al., 2009, p. 345).

Os coeficientes para a análise de regressão foram estimados pelo método dos Mínimos Quadrados Ordinários. Foram também tratados e analisados os principais pressupostos para a análise de regressão, sendo a normalidade dos resíduos admitida na expressividade da amostra; o pressuposto da homocedasticidade dos resíduos atendido mediante a correção de White, e, por meio de análise de correlação, verificou-se a ausência de multicolinearidade.

Tomando as variáveis definidas no tópico 3.3, tem-se o seguinte modelo geral de pesquisa:

Equação 1: Modelo geral da pesquisa

$$
\begin{gathered}
\text { IGOV }=\beta_{0}+\beta_{1} \text { DESEMP }+\beta_{2} \text { TAM }+\beta_{3} \text { ENDIV }+\beta_{4} \text { TANG }+\beta_{5} \text { CRESC }+\beta_{6} \text { TEMP } \\
+\beta_{7} A D R+\beta_{8} L I S T+\beta_{9} N D G C+\varepsilon
\end{gathered}
$$

Em que: IGOV: Índice de Governança Corporativa da Empresa i; DESEMP: Desempenho; TAM: Tama-nho; ENDIV: Endividamento; TANG: Tangibilidade; CRESC: Oportunidade de Crescimento; TEMP: Tempo de Existência; ADR: Emissão de ADR; LIST: Listagem na BM\&FBovespa; NDGC: Participação dos NDGC da BM\&FBovespa; i representa a i-ésima empresa; e $\mathcal{E}$ representa o termo de erro.

\subsection{DEFINIÇÃO DAS VARIÁVEIS}

\subsubsection{Variável Dependente: IGOV}

O IGOV foi criado com base nas recomendações dos Códigos das Melhores Práticas de Governança Corporativa do IBGC, cuja adoção proporciona melhorias na proteção dos direitos dos acionistas; da 
Cartilha de Recomendações da CVM (Comissão de Valores Mobiliários), que orienta o relacionamento entre órgãos e agentes, principalmente aqueles ligados a divulgação de informações contábeis e prestação de contas, como a auditoria e contabilidade; bem como dos regulamentos dos Níveis Diferenciados de Governança Corporativa (NDGC) da BM\&FBovespa, destinados às empresas com elevado padrão de governança corporativa (IBGC, 2013).

Segundo o IBGC (2013), o Código das Melhores Práticas de Governança Corporativa do IBGC proporciona melhorias na proteção dos direitos dos acionistas; a Cartilha de Recomendações da CVM (Comissão de Valores Mobiliários) orienta o relacionamento entre órgãos e agentes, principalmente aqueles ligados a divulgação de informações contábeis e prestação de contas, como a auditoria e contabilidade; e os regulamentos dos Níveis Diferenciados de Governança Corporativa (NDGC) da BM\&FBovespa são destinados às empresas com elevado padrão de governança corporativa.

Assim, o IGOV ficou composto por 21 perguntas binárias e objetivas, abrangendo três dimensões: composição e funcionamento do conselho de administração (9 quesitos), propriedade e direitos dos acionistas (7) e transparência (5), conforme Tabela 2.

Para quantificação do IGOV, cada resposta foi obtida a partir de dados extraídos dos relatórios anuais, estatutos, formulários de referência, atas de assembleias, e portal eletrônico das empresas da amostra, sendo atribuídos o valor "1" para cada resposta positiva e o valor "0" no caso contrário. Assim, o IGOV de cada empresa foi obtido da relação entre o número de respostas positivas e o total de perguntas, tal como se depreende da seguinte fórmula:

$$
I G O V_{t}=\frac{P}{T}=\frac{\sum_{i=1}^{n} g_{i}}{\sum_{i=1}^{m} g_{i}}
$$

Equação 2: Fórmula para o cálculo do IGOV

$$
I G O V_{i}=\frac{P}{T}
$$

Em que: $\mathrm{GGOV}_{\mathrm{i}}$ é o índice de governança para cada empresa $0 \leq \mathrm{IGOV}_{\mathrm{i}} \leq 1$. P é o total de respostas positivas obtidas pela empresa i eT é o número de itens constantes do índice.

Salienta-se que, quanto menor o IGOV, menor é o cumprimento das práticas de governança corporativa.

\subsubsection{Variáveis Independentes}

Constam do Quadro 1 a listagem das variáveis independentes definidas tópico 2.3, bem como a medida utilizada para quantificá-la e a relação esperada dessas variáveis com a variável dependente. Destaque-se que, assim como o IGOV, as variáveis independentes relacionam-se ao exercício de 2011, sendo a coleta dos dados efetuada entre agosto e outubro de 2012. 
Quadro 1: Variáveis independentes e efeitos esperados sobre a variável dependente

\begin{tabular}{|c|c|c|}
\hline VARIÁVEL INDEPENDENTE & MEDIDA DA VARIÁVEL INDEPENDENTE & RELAÇÃo ESPERADA \\
\hline Desempenho & Lucro Líquido / Patrimônio Líquido & Positiva/Negativa \\
\hline Tamanho & Logaritmo do Ativo Total & Positiva/Negativa \\
\hline Endividamento & Passivo Oneroso / Ativo Total & Positiva \\
\hline Tangibilidade & Ativo Imobilizado / Ativo Total & Negativa \\
\hline Oportunidade de Crescimento & $\begin{array}{c}\text { (Receita Liquida t - Receita Liquida t-1) / Ativo } \\
\text { Total t }\end{array}$ & Positiva \\
\hline Tempo de existência & $\begin{array}{c}\text { Tempo de registro na CVM } \\
\text { Emissão de ADR }\end{array}$ & Positiva \\
\hline Listagem na BM\&FBo de ADR & Positiva \\
\hline NDGC da BM\&FBovespa & $\begin{array}{c}\text { Participação nos NDGC da BM\&FBovespa (N1, } \\
\text { N2 e Novo Mercado) }\end{array}$ & Positiva \\
\hline
\end{tabular}

Fonte: Elaborado pelos autores.

Das variáveis independentes, sublinha-se que Emissão de ADR, Listagem na BM\&FBovespa e Participação nos NDGC da BM\&FBovespa são de natureza qualitativa, e, para quantificá-las, foram utilizadas as medidas correspondentes informadas no Quadro 1, atribuindo-se o valor 1 no caso positivo e o valor 0 no caso negativo. Quanto à Emissão de ADR, verificou-se essa informação a partir de lista disponibilizada no portal eletrônico da CVM. E, no que concerne à Listagem na BM\&FBovespa e à Participação dos Níveis Diferenciados de Governança Corporativa, colheram-se as informações necessárias no site da BM\&FBovespa.

Já as demais variáveis são de natureza quantitativa, sendo medidas a partir das informações do Quadro 1, as quais foram coletadas por meio do sistema de informações Economática ${ }^{\circledR}$.

\section{RESULTADOS}

\subsection{ANÁLISE DESCRITIVA DO IGOV}

Constituído o IGOV na forma descrita na metodologia, apresentam-se, na Tabela 2, os resultados obtidos para as 512 empresas considerando a frequência (f), em dados percentuais, das empresas cujas respostas foram positivas, sendo que $f_{1}$ refere-se às companhias listadas na BM\&FBovespa, $f_{2^{\prime}}$ àquelas não listadas na BM\&FBovespa, e $f_{t}$ significa a frequência total, considerando toda a amostra.

Quadro 1: Variáveis independentes e efeitos esperados sobre a variável dependente

\begin{tabular}{|c|c|c|c|}
\hline Composição e funcionamento do conselho de administração & $f_{1}$ & $f_{2}$ & $f_{t}$ \\
\hline 1. O conselho de administração possui entre cinco e onze membros? & 78,5 & 40,5 & 66,0 \\
\hline 2. O mandato do conselho de administração tem duração não superior a dois anos? & 70,3 & 36,9 & 59,4 \\
\hline 3. Os cargos de diretor presidente (CEO) e chairman são ocupados por pessoas diferentes? & 67,7 & 67,3 & 67,6 \\
\hline 4. O conselho de administração possui comitê de auditoria? & 20,3 & 8,3 & 16,4 \\
\hline 5. O conselho de administração possui comitê de remuneração? & 11,3 & 5,9 & 9,6 \\
\hline $\begin{array}{l}\text { 6. O comitê de auditoria é composto apenas por conselheiros não executivos, ou } \\
\text { independentes? }\end{array}$ & 1,2 & 0,6 & 1,0 \\
\hline $\begin{array}{l}\text { 7. O comitê de remuneração é composto apenas por conselheiros não executivos, ou } \\
\text { independentes? }\end{array}$ & 2,0 & 0,0 & 1,4 \\
\hline 8. $O$ diretor presidente (CEO) participa do conselho de administração? & 52,0 & 35,1 & 46,5 \\
\hline 9. O conselho de administração possui pelo menos $1 / 5$ de membros independentes? & 32,0 & 5,4 & 23,2 \\
\hline Propriedade e direitos dos acionistas & & & \\
\hline
\end{tabular}




\begin{tabular}{|c|c|c|c|}
\hline 10. A convocação para a realização da assembleia observa a antecedência de 30 dias & 9,8 & 1,8 & 13,9 \\
\hline $\begin{array}{l}\text { 11. A companhia facilita a participação dos sócios em assembleia por meio do voto por } \\
\text { procuração (proxy voting) e outros canais, como assinatura eletrônica, certificação digital, } \\
\text { agentes de voto (voting agents)? }\end{array}$ & 31,4 & 17,9 & 26,9 \\
\hline $\begin{array}{l}\text { 12. A companhia disponibiliza em seu portal eletrônico o manual contendo instruções } \\
\text { para participação em assembleia? }\end{array}$ & 13,1 & 1,8 & 9,4 \\
\hline 13. A companhia concede tag along além do exigido por lei? & 35,8 & 9,5 & 27,1 \\
\hline $\begin{array}{l}\text { 14. A companhia utiliza mecanismos de medição e arbitragem para a resolução dos } \\
\text { casos de conflito entre sócios? }\end{array}$ & 49,4 & 7,8 & 35,7 \\
\hline 15. O grupo controlador possui menos da metade das ações com direito a voto? & 39,5 & 14,9 & 31,4 \\
\hline $\begin{array}{l}\text { 16. A proporção das ações sem direito a voto corresponde a menos de } 1 / 5 \text { do capital } \\
\text { social? }\end{array}$ & 54,9 & 82,7 & 64,1 \\
\hline \multicolumn{4}{|l|}{ Transparência } \\
\hline $\begin{array}{l}\text { 17. O portal eletrônico da companhia divulga para o mercado o conteúdo de suas } \\
\text { teleconferências com investidores? }\end{array}$ & 39,2 & 6,5 & 28,5 \\
\hline $\begin{array}{l}\text { 18. A companhia divulga sua política de dividendos no relatório anual ou em seu portal } \\
\text { eletrônico? }\end{array}$ & 57,6 & 29,2 & 48,2 \\
\hline $\begin{array}{l}\text { 19. A companhia divulga os fatores de risco a que fica exposta, nos moldes da ICVM } \\
480 / 2009 \text { ? }\end{array}$ & 91,0 & 86,9 & 89,6 \\
\hline 20. A companhia divulga a política de negociação de ações de seus administradores? & 61,9 & 17,3 & 47,3 \\
\hline $\begin{array}{l}\text { 21. O portal eletrônico da companhia disponibiliza área dedicada à governança } \\
\text { corporativa? }\end{array}$ & 63,1 & 19,0 & 48,6 \\
\hline
\end{tabular}

Fonte: Elaborado pelos autores

No que tange à frequência total $\left(f_{\mathrm{t}}\right)$, os resultados revelam que, na grande maioria das empresas, os cargos de diretor presidente (CEO) e chairman são ocupados por pessoas distintas (67,6\%), e o conselho de administração possui quantitativo adequado (66\%), o que significa uma adequada estrutura da composição do conselho de administração nesses quesitos, indo ao encontro das boas práticas de governança corporativa.

Esses resultados demonstram que, nesses quesitos, boa parte das empresas da amostra possuem um conselho de elevada qualidade. Conforme descreve Correia, Amaral e Louvet (2014, p. 46), esses conselhos são caracterizados por possuirem "participação elevada de diretores independentes, externos à firma; separação das funções de diretor geral da companhia e de presidente do Conselho; e pequena quantidade de conselheiros".

Entretanto, ainda no que concerne à composição e funcionamento do conselho de administração, observa-se que apenas $16,4 \%$ das empresas possuíam comitê de auditoria, sendo que em apenas $1 \%$ delas esse comitê compunha-se de conselheiros não executivos, ou independentes. Além disso, o comitê de remuneração estava presente em apenas $9,6 \%$ das empresas, sendo que em apenas 1,4\% delas a composição desse órgão constituía-se de conselheiros não executivos, ou independentes.

No tocante a propriedade e direitos dos acionistas, a única pergunta que obteve resposta positiva de mais da metade da amostra foi aquela relacionada à proporção das ações sem direito a voto, alcançando expressivos $64,1 \%$ das empresas. As outras seis perguntas do grupo receberam resposta positiva em proporções que variam entre $9,4 \%$ e $35,7 \%$ da amostra, o que pode ser considerado negativo, já que na maioria das empresas os direitos dos acionistas não vêm sendo preservados, ou a propriedade das empresas não está de acordo com as boas práticas de governança corporativa.

Observa-se ainda que o item 19 alcançou o maior número de respostas positivas, significando dizer que quase $90 \%$ das empresas apresentam aos stakeholders os fatores de risco a que ficam expostas, em observância à ICVM 480/2009. Essa divulgação é importante no tocante à transparência, pois o conhecimento dos riscos a que as companhias ficam expostas auxilia os usuários externos no processo decisório.

No grupo alusivo à transparência, chama-se atenção para o fato de que, em pouco menos de metade da amostra, há uma área em cada portal eletrônico dedicada a governança corporativa. Tra- 
ta-se de proporção considerada baixa, dada a importância da transparência das informações para o fortalecimento das empresas e o desenvolvimento do mercado de capitais, sendo relevante que mais empresas disponibilizem esse espaço para os usuários. Ademais, em apenas $28,5 \%$ das companhias o portal eletrônico disponibiliza o conteúdo de suas teleconferências com investidores, índice considerado baixo diante da relevância da matéria.

Esse resultado vai de encontro às boas prática de governança corporativa pois, conforme Correia, Amaral e Louvet (2011, p. 50) a qualidade das informações financeiras publicadas pela empresa permite reduzir a assimetria de informações entre os atores internos e os investidores externos, diminuindo, assim, os conflitos de interesse. Para os autores, "a transparência refere-se a todas as informações necessárias aos investidores externos para julgar se seus direitos são preservados nas decisões tomadas na empresa".

Com relação às frequências obtidas pelas empresas listadas na BM\&FBovespa $(f 1)$, assim como pelas demais participantes da amostra ( $f 2$ ), sublinha-se que somente no item 16 as empresas do segundo grupo apresentaram maior frequência de respostas positivas, o que indica uma melhor governança corporativa tão-somente no tocante a esse quesito.

Nos demais itens, as empresas listadas apresentaram maior frequência de respostas positivas, à exceção do item 3, que registrou equilíbrio nos dois grupos.

Esses resultados, a priori, corroboram a hipótese $\mathrm{H} 8$ da presente pesquisa, indicando que a listagem na BM\&FBovespa exerce influência positiva sobre as práticas de governança corporativa. Ou seja, há indício de que as empresas listadas têm melhor governança corporativa, comparativamente às demais participantes da amostra, o que é melhor analisado no tópico 4.2, a partir dos testes estatísticos ali apresentados.

Tabela 3: Estatística descritiva das 512 empresas que apresentaram IGOV (\%)

\begin{tabular}{|c|c|c|c|c|c|c|}
\hline & Média & Mediana & Moda & Desvio-padrão & Mínimo & Máximo \\
\hline Listadas e Não Listadas & 36,23 & 33,33 & 23,81 & 18,75 & 4,76 & 85,71 \\
\hline Listadas & 42,59 & 42,85 & 23,81 & 18,52 & 4,76 & 85,71 \\
\hline Não Listadas & 23,67 & 23,8 & 14,29 & 11,46 & 4,76 & 57,14 \\
\hline
\end{tabular}

Fonte: Elaborado pelos autores.

A Tabela 3 apresenta a estatística descritiva do IGOV, na qual se observa que as empresas da amostra atenderam, em média, a 36,23\% das práticas de governança corporativa, e o desvio-padrão, ao se situar abaixo da média e da mediana, revela uma baixa dispersão entre as pontuações obtidas pelas empresas. Essa média pode ser considerada baixa, na medida em que as empresas atenderam, em média, a menos da metade das práticas de governança corporativas recomendadas pelo IBGC, pela CVM e pela BM\&FBovespa.

Por outro lado, destaca-se que as empresas listadas na BM\&FBovespa apresentaram uma média de IGOV superior ao daquelas não listadas, levando a indícios de que possuem melhor governança corporativa que as demais.

Além disso, nem todas as empresas apresentaram grau de atendimento inferior a 50\%, destacando-se que a empresa com maior IGOV atendeu a $85,71 \%$ das boas práticas de governança corporativa analisadas, enquanto a que obteve o menor valor atendeu a 4,76\% delas. Ressalta-se ainda que a empresa com maior IGOV (85,71\%) pertence ao grupo de empresas listadas na BM\&FBovespa. 


Tabela 4: Estatística descritiva - Quartil - 512 empresas que apresentaram IGOV (\%)
\begin{tabular}{|c|c|c|c|c|}
\hline & $\mathbf{1}^{\circ}$ Quartil & $\mathbf{2}^{\circ}$ Quartil & $\mathbf{3}^{\circ}$ Quartil & $\mathbf{4}^{\circ}$ Quartil \\
\hline Listadas e Não Listadas & 23,8 & 33,33 & 52,38 & 85,71 \\
\hline Listadas & 28,57 & 42,85 & 57,14 & 85,71 \\
\hline Não Listadas & 14,28 & 23,8 & 28,57 & 57,14 \\
\hline
\end{tabular}

Fonte: Elaborado pelos autores

Na Tabela 4, tem-se a distribuição das pontuações obtidas. Assim, que 25\% das empresas apresentaram IGOV igual ou inferior a 23,8\%, enquanto em 75\% das empresas o IGOV foi igual ou inferior a $52,38 \%$. Extrai-se ainda que pouco mais de $25 \%$ da amostra obtiveram IGOV superior a 50\%, atendendo a mais da metade das boas práticas de governança corporativa consideradas no presente estudo.

Percebe-se também que 75\% das empresas não listadas obtiveram um IGOV igual ou inferior a $28,57 \%$ (3० Quartil), sendo que, nas empresas listadas, apenas 25\% das empresas obtiveram um IGOV nesses mesmos valores (1० Quartil).

\subsection{DETERMINANTES DAS BOAS PRÁTICAS DE GOVERNANÇA CORPORATIVA}

No intuito de verificar os determinantes das boas práticas de governança corporativa, inicialmente, efetuou-se análise de correlação para verificar as possíveis associações entre a variável dependente e as variáveis independentes, resultando em sete associações significantes positivas, conforme Tabela 5.

Tabela 5: Matriz de correlação das variáveis

\begin{tabular}{|l|c|c|c|c|c|c|c|c|c|}
\hline & DES & TAM & END & TANG & OPC & TEMP & ADR & LIST & NDGC \\
\hline IGOV & $-0,063$ & $0,458^{* * *}$ & $0,248^{* * *}$ & $-0,038^{* *}$ & $0,153^{* * *}$ & $-0,202^{* * *}$ & 0,079 & $0,480^{* * *}$ & $0,735^{* * *}$ \\
\hline
\end{tabular}

Fonte: Elaborado pelos autores.

Posteriormente, foi feita análise de regressão, cujos resultados podem ser verificados na Tabela 6.

Tabela 6: Análise de Regressão

\begin{tabular}{|c|c|c|c|c|}
\hline Variável & Expectativa & Coeficiente & $\mathrm{t}$ teste & P-valor \\
\hline $\begin{array}{c}\text { Desempenho } \\
\text { Tamanho } \\
\text { Endividamento } \\
\text { Tangibilidade } \\
\text { Oportunidade de Crescimento } \\
\text { Tempo de Existência } \\
\text { Emissão de ADR } \\
\text { Listagem na BM\&FBovespa } \\
\text { Participação nos NDGC } \\
\text { Constante }\end{array}$ & $\begin{array}{c}+/- \\
+/- \\
+ \\
- \\
+ \\
+ \\
+ \\
+ \\
+\end{array}$ & $\begin{array}{r}0,009 \\
0,027 \\
0,073 \\
-0,051 \\
0,065 \\
-0,001 \\
0,039 \\
0,079 \\
0,213 \\
0,106\end{array}$ & $\begin{array}{l}1,100 \\
5,460 \\
2,720 \\
-2,220 \\
1,740 \\
-2,750 \\
0,860 \\
5,600 \\
13,720 \\
4,050\end{array}$ & $\begin{array}{l}0,274 \\
0,000^{* * *} \\
0,007^{* * *} \\
0,027^{* *} \\
0,082^{*} \\
0,006^{* * *} \\
0,390 \\
0,000^{* * *} \\
0,000^{* * *} \\
0,000^{* * *}\end{array}$ \\
\hline$R^{2} a=62,47 \%$ & \multicolumn{2}{|c|}{ Teste $\mathrm{F}=95,08^{* * *}$} & \multicolumn{2}{|c|}{$N=428$} \\
\hline \multicolumn{5}{|c|}{ Significância estatística aos níveis de $1 \%, 5 \%$ e $10 \%$ indicada por ***,** e*, respectivamente. } \\
\hline Teste Breusch-Pagan 1,93 & & & & \\
\hline
\end{tabular}

Fonte: Elaborado pelos autores.

Inicialmente, ressalte-se que o teste de Breusch-Pagan apresentou-se significante, 1,93, sendo a regressão apresentada com a correlação de White. Restou, pois, atendido o pressuposto da heterodascidade.

Os resultados expostos na Tabela 6 indicam que as variáveis independentes selecionadas explicam $62,47 \%$ das oscilações na variável dependente, conforme $R^{2}$ ajustado, bem como que o modelo é sig- 
nificante considerando um nível de significância de 0,01. Observa-se ainda que, das variáveis independentes selecionadas, apenas desempenho e emissão de ADR não apresentaram significância estatística.

Observa-se uma relação positiva significante no nível de 1\% entre tamanho e nível de governança corporativa, sugerindo que empresas maiores tendem a adotar melhores práticas de governança corporativa. Corroboram nesse sentido Silveira e Barros (2008), Ariff, Ibrahim e Othman (2007) e Silveira et al. (2009).

Isso ocorre em virtude, por exemplo, do maior volume de capital de que as empresas maiores dispõem para investir na adoção dessas práticas, bem como por estarem mais expostas ao mercado e sofrerem maior pressão externa para apresentar boa governança corporativa.

A variável endividamento também se mostrou associada positivamente com a variável dependente ao nível significante de $1 \%$, indicando que as empresas mais endividadas tendem a apresentar melhor governança corporativa.

Conforme esperado, os resultados expostos na Tabela 6 também mostram que, ao nível de significância de 5\%, a tangibilidade dos ativos associa-se negativamente às boas práticas de governança corporativa, ou seja, as empresas que possuem menor proporção de bens tangíveis em relação aos intangíveis tendem a adotar melhor governança corporativa.

Segundo a teoria, empresas com maior proporção de bens intangíveis enfrentam mais dificuldade de controle sobre os bens, o que as leva a adotar melhores práticas de governança corporativa. Por outro, a maior proporção de bens tangíveis é uma característica que tornaria a empresa menos susceptível à adoção de melhores práticas de governança. Esse resultado alinha-se ao entendimento de Almeida et al. (2010a).

Já com a variável oportunidade de crescimento, obteve-se associação positiva, significante ao nível de $10 \%$, comungando os estudos de Dunerv e Kim (2005) e Klapper e Love (2002). Isso significa que essas empresas, que em tese precisam captar mais recursos no mercado para financiar o seu crescimento, apresentam melhor governança corporativa que aquelas que não tem essa necessidade.

No tocante ao tempo de existência, ao contrário do esperado, identificou-se uma relação negativa significante no nível de $1 \%$ com o nível de governança corporativa, indicando que as empresas mais novas tendem a adotar melhores práticas de governança corporativa. Não obstante o que se esperava, esse resultado possui respaldo em parte da literatura que afirma que as empresas mais novas apurariam maior benefício marginal com a adoção dessas práticas, sendo, portanto, mais propensas a adotá-las, tal como verificado por Almeida et al. (2010a).

Há corrente que entende que aquelas empresas com maior tempo de existência é que deveriam apresentar maior governança, pois não se arriscariam a praticar má governança e afetar a imagem construída ao longo do tempo. Ocorre que, nos resultados encontrados, verificou-se que as empresas mais novas apresentam melhor governança que as empresas mais antigas.

A princípio, isso não significa que as práticas de governança das empresas mais antigas são ruins, mas apenas que são inferiores aquelas praticadas pelas empresas com menor tempo de existência. Essas empresas obtém um maior benefício marginal com a adoção da boa governança por saírem de patamar nulo, de ausência de práticas de governança, então, quando iniciam, são logo reconhecidas por isso.

Além disso, a listagem na BM\&FBovespa e a participação nos NDGC mostraram-se associados positivamente às boas práticas de governança corporativa ao nível de $1 \%$, alinhando-se ao que foi verificado por Silveira et al. (2009). Isso significa que essas empresas possuem melhor governança, 
pressupondo uma administração mais transparente, com diminuição da assimetria de informações e respeito aos investidores.

Ainda para atender ao objetivo do estudo, separou-se a amostra em empresas listadas e não listadas e realizou-se análise de regressão no intuito de verificar se há diferença nos determinantes da adoção das boas práticas de governança corporativa entre esses dois grupos de empresas.

Foi feita, inicialmente, análise de correlação para verificar as possíveis associações entre a variável dependente e as variáveis independentes, conforme Tabela 7. Ressalta-se que, na segunda linha, são reapresentados os resultados expostos na Tabela 5 para fins comparativos, e nas linhas 3 e 4 são apresentadas, respectivamente, as correlações para as empresas listadas e não listadas em bolsa.

Tabela 7: Matriz de correlação das variáveis

\begin{tabular}{|c|c|c|c|c|c|c|c|c|c|}
\hline & DES & TAM & END & TANG & CRESC & TEMP & ADR & LIST & NDGC \\
\hline \multirow{3}{*}{ IGOV } & $-0,063$ & $0,458^{* * *}$ & $0,248^{* * *}$ & $-0,038^{* *}$ & $0,153^{* * *}$ & $-0,202^{* * *}$ & 0,079 & $0,480^{* * *}$ & $0,735^{* * *}$ \\
\hline & $-0,060$ & $0,410^{* * *}$ & $0,209^{* * *}$ & $-0,168^{* * *}$ & $0,154^{* * *}$ & $-0,389^{* * *}$ & 0,073 & . & $0,714^{* * *}$ \\
\hline & $-0,088$ & $0,435^{* * *}$ & $0,400^{* * *}$ & $0,184^{* *}$ & $0,064^{* *}$ & $-0,214^{* *}$ & $0,200 * *$ & . & . \\
\hline
\end{tabular}

Fonte: Elaborado pelos autores

Apresentam-se, na Tabela 8, os resultados obtidos, sendo ainda reapresentada a regressão para a amostra completa, com fins comparativos.

Tabela 8: Análise de Regressão

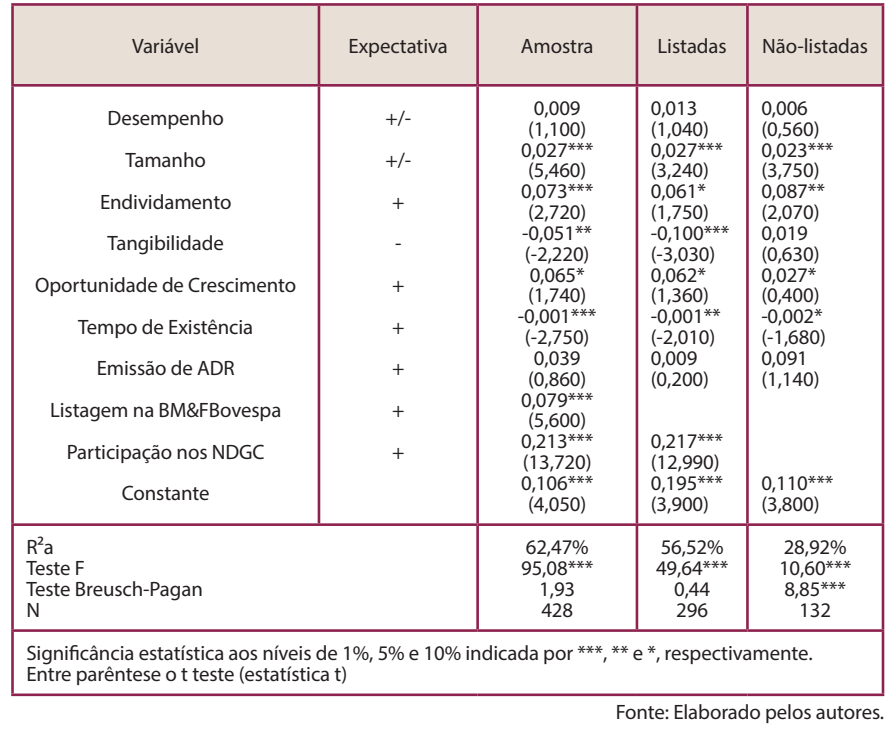

Na Tabela 8, verifica-se que as variáveis independentes selecionadas explicam 52,52\% e 28,92\% das oscilações na variável dependente, considerando-se, respectivamente, as empresas listadas e não listadas em bolsa, conforme $\mathrm{R}^{2}$ ajustado. Os resultados mostram ainda que os modelo apresentados são significantes considerando um nível de significância de 0,01.

Observa-se que as variáveis tamanho, endividamento, oportunidade de crescimento e tempo de existência mostraram-se associadas às boas práticas de governança corporativa nos três modelos de regressão. Ou seja, não houve diferença entre empresas listadas e não listadas em bolsa, ressalvando-se a significância dessas variáveis. 
No mesmo sentido, quando se considerou apenas as empresas listadas em bolsa, a participação nos NDGC continuou como variável explicativa significante ao nível de $1 \%$, tal como ocorreu com a amostra completa. Logo, a participação nos NDGC mostrou-se associada positivamente às boas práticas de governança corporativa nos dois modelos.

Já a variável tangibilidade, que se apresentou como variável explicativa ao nível de $5 \%$ quando se considerou a amostra completa, apresentou-se significante, ao nível de 1\%, apenas para as empresas listadas em bolsa. Para as empresas não listadas em bolsa, essa variável não apresentou significância estatística para explicar a adoção das boas práticas de governança corporativa dessas empresas.

\section{CONCLUSÃO}

A pesquisa objetivou investigar os fatores determinantes dos níveis de aderência às boas práticas de governança corporativa pelas companhias registradas na CVM, diferenciando-se empresas listadas e não listadas em bolsa. As práticas de governança das empresas foram medidas por um IGOV, sendo os dados, posteriormente, submetidos a análises descritiva e de regressão.

A população reuniu 554 empresas brasileiras de capital aberto não financeiras registradas na CVM, sendo a amostra formada por 512 empresas. A análise de regressão contou com 428 dessas empresas, 296 listadas em bolsa e 132, não.

As associações verificadas para a amostra completa foram as mesmas que se verificou quando se levou em consideração apenas as empresas listadas em bolsa. Já para as empresas não listadas, diferente do observado nas outras regressões, não se verificou associação significante entre a adoção de boas práticas de governança corporativa e a variável tangibilidade.

Assim, das hipóteses apresentadas, confirmaram-se aquelas que associavam as boas práticas de governança corporativa às variáveis endógenas tamanho, endividamento, oportunidade de crescimento, listagem em bolsa e participação dos NDGC. Quanto ao tempo de existência, esperava-se uma associação positiva, ou seja, que quanto mais tempo tivesse a empresa, melhor fosse sua governança, mas o resultado foi o inverso, indicando, nas três regressões realizadas, que as empresas com menor tempo de existência apresentam melhor governança.

Quanto à hipótese que associou as boas práticas de governança à variável tangibilidade, os resultados se confirmaram para a amostra completa e para as empresas listadas em bolsa. Logo, não houve a confirmação dessa hipótese para as empresas não listadas em bolsa, o que significa que, nessas empresas, a composição patrimonial da entidade quanto aos bens tangíveis e intangíveis não interfere na governança praticada.

Os resultados apresentados corroboram a hipótese da pesquisa de que o nível de governança corporativa das empresas registradas na CVM está associado às variáveis endógenas das firmas, bem como que os resultados podem variar entre empresas listadas e não listadas em bolsa. Assim, os resultados seguem a mesma linha da afirmação de Silveira, Barros e Perobelli (2008) de que, quando submetidas ao mesmo ambiente contratual, as empresas tendem a apresentar práticas de governança corporativa em função de suas características observáveis.

Entretanto, o fato de as variáveis independentes desempenho e emissão de ADR não terem apresentado significância estatística na análise de regressão, vai de encontro aos resultados apresentados por Silveira e Barros (2008), Leão (2010), Silveira et al. (2009) e Klapper e Love (2002), no primeiro caso e por Klapper e Love (2002), Silva e Leal (2004) e Silveira e Barros (2008), no último. 
Nesse sentido, o presente estudo contribui para a academia no sentido de mostrar que as variáveis endógenas associadas à boa governança podem variar entre empresas listadas e não listadas em bolsa. Considerar na amostra apenas empresas listadas fornece um resultado que não pode ser generalizado para empresas não listadas, e isso deve ser ressaltado nos estudos.

Em termos de mercado, mostra-se que realmente aquelas empresas listadas em bolsa, que são submetidas à um ambiente contratual diferente e que tem que mostrar segurança ao investidor, adotam melhores práticas de governança, pressupondo uma administração mais transparente, com redução da assimetria de informações.

Sugere-se que estudos posteriores verifiquem a adoção das boas práticas de governança corporativa nas empresas listadas na CVM tomando por base outros exercícios, para que, além dos determinantes dessas práticas, seja também verificada a sua evolução.

\section{REFERÊNCIAS}

Almeida, Moisés Araújo et al. (out./dez, 2010a). Determinantes da qualidade das práticas de governança corporativa das empresas brasileiras de capital aberto que possuem investimentos públicos. Revista Brasileira de Gestão de Negócios, São Paulo, 12(37), pp. 369-387.

Evolução da qualidade das práticas de governança corporativa: um estudo das empresas brasileiras de capital aberto não listadas em bolsa. RAC, Curitiba, v. 14, n. 5, p. 907-924, set./out. 2010b.

\& Santos, Joséte Florêncio dos. (jul./ago./set. 2009). Relação entre variáveis endógenas e a qualidade das práticas de governança corporativa das empresas brasileiras de capital aberto não listadas em bolsa. Revista de Informação Contábil, 2(4), pp. 17-37.

Aragão, Lindenberg Araújo et al. (2012). Fatores motivacionais à adoção de melhores práticas de governança corporativa. Base (Unisinos), 9, pp. 1-15.

Ariff, Akmalia Mohamad., Ibrahim, Muhd Kamil. e Othman, Radiah. (2007). Determinants of firm level governance: Malaysian evidence. Emerald Group Publishing Limited, 7(5), pp. 562-573.

Bhagat, Sanjai \& Bolton, Brian. (2008). Corporate governance and firm performance. Journal of Corporate Finance, 14, pp. 257-273.

Black, Bernard S., Jang, Hasung e Kim, Woochan. (2003). Does Corporate Governance Affect Firm Value? Evidence from Korea, The Journal of Law, Economics \& Organization, 22.

Black, Bernard. S., Carvalho, Antônio Gledson de e Gorga, Érica. (2012). What matters and for which firms for corporate governance in emerging markets? Evidence from Brazil (and other BRIK countries), Journal of Corporate Finance, 18, pp. 934-952.

. (2010). Corporate governance in Brazil, Emerging Markets Review, 11, pp. 21-38. 
Braga-Alves, Marcus V. \& Shastri, Kuldeep. (2011). Corporate Governance. Valuation, and Performance: Evidence from a Voluntary Market Reform in Brazil, Financial Management, 40, pp. 139-157.

Carvalho, Antônio Glédson de. (jul./set. 2002). Governança corporativa no Brasil em perspectiva. Revista de Administração, São Paulo, 37(3), pp. 19-32.

. (2003). Efeitos da migração para os níveis diferenciados de governança corporativa da BM\&FBovespa. Disponível em: <http://www.bmfbovespa.com.br/Pdf/uspniveis.pdf> Acesso em: 04 set. 2014.

Correia, Laise Ferraz; Amaral, Hudson Fernandes; Louvet, Pascal. Um Índice de Governança Corporativa para Empresas no Brasil. Revista Contabilidade \& Finanças (Online), v. 22, p. 45-63, 2011.

Determinantes da eficiência de conselhos de administração de empresas negociadas na BM\&FBopvespa. Revista de Contabilidade e Organizações, v. 8, p. 46-57, 2014.

Cunha, Jacqueline Veneroso Alves da; Ribeiro, Maísa de Souza. Divulgação voluntária de informações de natureza social: um estudo nas empresas brasileiras. Revista de Administração Eletrônica, São Paulo, v. 1, n. 1, jan./jun. 2008.

Durnev, Art; Kim, Han. To steal or not to steal: firm attributes, legal environment, and valuation. The Journal of Finance, v. 60, n. 3, p. 1.461-1.493, jun. 2005.

Fávero, Luiz Paulo et al. Análise de dados: modelagem multivariada para a tomada de decisões. Rio de Janeiro: Campus, 2009.

Healy, Paul M.; Palepu, Krishna G. Information asymmetry, corporate disclosure, and the capital markets: a review of the empirical disclosure literature. Journal of Accounting and Economics, v. 31, p. 405-440, 2001.

IBGC. Instituto Brasileiro de Governança Corporativa. Código das Melhores Práticas. 2013. Disponível em <http://www.ibgc.org.br/CodigoMelhoresPraticas.aspx>. Acesso em: 23 mar. 2013.

Jensen, Michael C.; Meckling, Willian H. Theory of the firm: managerial behavior, agency costs and ownership structure. Journal of Financial Economics, v. 3, n. 4, p. 305-360, oct. 1976.

Klapper, Leora, Love, Inessa. Corporate governance, investor protection, and performance in emerging markets. World Bank Policy Research Working Paper, n. 2.818, apr. 2002.

Lameira, V. J.; Lee Ness Jr, W. Os Determinantes da Qualidade da Governança Praticada pelas Companhias Abertas Brasileiras. Revista de Negócios, v. 16, n. 3, p. 33-52, 2011.

Leão, Alexandre de Souza Baptista de. Determinantes da governança corporativa no Brasil. 2010. 80 f. Dissertação (Mestrado em Administração) - Faculdade de Economia e Finanças, Ibmec, Programa de Pós-Graduação e Pesquisa em Administração e Economia, Rio de Janeiro, 2010. 
Shleifer, A.; Vishny, R. W. A survey of corporate governance. The Journal of Finance, v. 52, n. 2, p. 737783, 1997.

Silva, André Luiz Carvalhal da; Leal, Ricardo Pereira Câmara. Corporate governance index, firm valuation and performance in Brazil. Revista Brasileira de Finanças, v. 3, n. 1, p. 1-18, 2004.

Silveira, Alexandre Di Miceli da. Governança corporativa, desempenho e valor da empresa no Brasil. 2002. 165 f. Dissertação (Mestrado em Administração) - Faculdade de Economia, Administração e Contabilidade, Universidade de São Paulo, São Paulo, 2002.

; Barros, Lucas Ayres Barreira de Campos. Determinantes da qualidade da governança corporativa das companhias abertas brasileiras. READ, ed. 61, v. 14, n. 3, p. 1-28, set./dez. 2008.

Famá, Rubens. Estrutura de governança e desempenho financeiro nas companhias abertas brasileiras: um estudo empírico. Caderno de Pesquisas em Administração, São Paulo, v. 10, n. 1, p. 5771, jan./mar. 2003.

. Perobelli, Fernanda Finotti Cordeiro. Governança Corporativa e os Determinantes da Estrutura de Capital: Evidências Empíricas no Brasil. RAC, Curitiba, v. 12, n. 3, p. 763-788, jul./set. 2008.

et al. Evolution and determinants of firm-level corporate governance quality in Brazil. Revista de Administração, São Paulo, v. 44, n. 3, p. 173-189, jul./ago./set. 2009 